\title{
Inspection and Analysis of Air Quality Forecast Effect by Using 4 Years Data in Ningxia Base on the Newest National Standard
}

\author{
Shao Jian ${ }^{1,2,3, ~ *, ~ Y a n g ~ Y u a n y u a n ~}{ }^{2,3}$, Chen Min $^{3}$, Du QingYang ${ }^{3}$ \\ ${ }^{1}$ Key Laboratory of Characteristic Agro-meteorological Disaster Monitoring and Early Warning and Risk Management in Arid Regions, CMA, \\ Yinchuan, China \\ ${ }^{2}$ Ningxia Meteorological Observatory, Yinchuan, China \\ ${ }^{3}$ Yinchuan Meteorological Bureau, Yinchuan, China
}

Email address:

shaosdh@163.com (ShaoJian)

*Corresponding author

\section{To cite this article:}

Shao Jian, Yang Yuanyuan, Chen Min, Du QingYang. Inspection and Analysis of Air Quality Forecast Effect by Using 4 Years Data in Ningxia Base on the Newest National Standard. Science Discovery. Vol. 9, No. 3, 2021, pp. 108-113. doi: 10.11648/j.sd.20210903.14

Received: March 26, 2021; Accepted: May 13, 2021; Published: May 24, 2021

\begin{abstract}
In this paper, the characteristics of air quality index, air quality grade, pollutant concentration and the type of primary pollutant were tested, and the forecast result was analyzed by the daily observe and forecast data of air quality index, concentration of pollutants, primary pollutant types in Yinchuan from January 1st 2015 to December 31th 2018. The results showed that the forecast result was not satisfactory for the air quality grades. The annual TS of air quality grade forecast in Yinchuan were increased year by year, which between $20 \%$ and $40 \%$, but the point out rates (PO) and the not hit rates $(\mathrm{NH})$ were high, which showed a decreasing trend. For the weather with a good air quality grade, the TS were significantly higher than that of other grades. The average absolute error of the air quality index (AQI) forecast decreased over the year, and presented seasonal fluctuation characteristics, but increased with the pollution grades. The model was good at predictive capacity of primary pollutant types, which TS generally reached $40 \%-60 \%$. There was little difference in the forecast results of each predictable scale by the simple and objective revise, that was to say, the forecast capability of the product had not been improved obviously with the variation of forecast timeliness, so that the forecast product should strive for more room for its improvement, which still has a long way to go.
\end{abstract}

Keywords: Air Quality Index, Pollutant Concentration, Primary Pollutant, Predictive Capacity

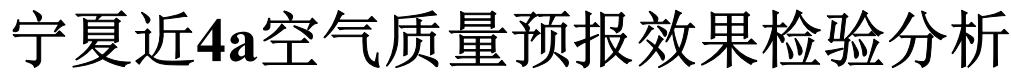

邵建 ${ }^{1,2,3^{*}}$, 杨苑媛 ${ }^{2,3}$, 陈敏 ${ }^{3}$, 杜晴阳 ${ }^{3}$

${ }^{1}$ 中国气象局旱区特色农业气象灾害监测预警与风险管理重点实验室, 银川, 中华人民共和国

2宁夏气象防灾减灾重点实验室, 银川, 中华人民共和国

3银川市气象局, 银川, 中华人民共和国

\section{邮箱}

shaosdh@163.com（邵建）

摘要：本文利用2015年1月1日至2018年12月31日宁夏五市逐日空气质量指数、污染物浓度、首要污染物类型等实况监 测数据以及空气质量预报资料, 分析了 $\mathrm{AQI}$ 指数、空气质量等级、首要污染物浓度及类型分布特征, 并对其预报效果 进行了检验分析。结果表明：该预报对宁夏空气质量等级的预报效果不太理想。研究时段内，宁夏空气质量等级预报 
的年度平均TS评分在 $20 \%-40 \%$ 之间, 漏报率和空报率较高。TS评分随年际变化呈递增趋势, 漏报率和空报率呈递减趋 势。空气质量等级为良时,TS评分显著高于其他等级。AQI指数预报的平均绝对误差逐年减小, 且呈现季节性的波动变 化特征, 并随污染等级增加总体上呈递增趋势。首要污染物类型的预报能力相对较好, TS评分普遍达 $40 \%-60 \%$ 。经简 单客观订正的银川市空气质量预报, 各项预报要素的各预报时次检验结果差异较小, 即该预报产品的预报能力并未随 预报时次缩短而出现较为明显的提升，表明该预报产品还有较大的提升空间。

关键词: 空气质量指数, 污染物浓度, 首要污染物, 预报水平

\section{1. 引言}

环境问题已成为人类面临的严峻挑战之一, 随着绿色 发展理念的深入人心, 公众的生态保护意识不断增强, 对 大气污染状况和空气质量水平日益关注。良好的大气环境 是城市可持续发展的重要资源, 如何在搞好经济发展的同 时兼顾生态环境保护已成为国内外关心的热点问题。开展 城市空气质量预报工作, 能够为公众出行、环境污染变化 动态监视、污染事件应对提供参考。通过对空气质量预报 进行统计检验, 能够客观定量反映预报能力, 了解预报模 式在实际应用中存在的问题，从而改进和提高预报水平。

近年来, 国内学者在空气质量预报及其预报检验等方 面做了大量的深入研究方面做了大量研究。周丽等建立北 京地区 $\mathrm{PM}_{2.5}$ 统计预报模型, 尝试对污染物浓度做出预报 [1]; 魏玉香等研究了南京地区 $\mathrm{PM}_{2.5}$ 浓度的时空变化特征, 并利用同时期气象资料分析了 $\mathrm{PM}_{2.5}$ 浓度与气象条件的关 系[2]。李晓岗等利用统计方法对国家气象中心下发的 CUACE模式指导产品进行应用检验, 发现模式输出的污 染物浓度水平普遍存在偏低的现象, 需经过方法订正才能 提高预报准确率 [3]。麦健华等对基于GRAPES-CMAQ模 式的广东省中山市空气质量预报系统开展了预报效果评 估, 得出了等级预报TS评分[4]。冯震等对呼和浩特市 2015 年冬季空气质量指导预报从单时次预报、逐日预报、过程 预报 3 个方面进行了检验分析 [5]。刘慧等从能见度和空气 质量两个方面, 通过对比检验发现随着能见度降低, 各数 值模式的预报能力均逐渐下降, 随着空气质量下降, 各数 值模式 $\mathrm{AQI}$ 的预报能力均逐渐下降, 各数值模式对 $\mathrm{PM}_{2.5}$ 浓度的预报值普遍较观测值偏低[6]。张珺等利用前一日污 染物浓度和当日气象要素日均值为预报因子, 建立空气质 量预报模型, 并对石家庄和邢台冬季空气质量等级预报准 确率进行检验[7]。杨关盈、张璘、岳旭等分别对不同地区 的空气质量预报开展检验, 均得出人工订正好于模式可用 性的结论[8-10]。王晓敏等利用国家气象中心、北京和河 北等空气质量预报产品, 对石家庄市夏季主要污染物 $\mathrm{PM}_{2.5} 、 \mathrm{PM}_{10}$ 和 $\mathrm{SO}_{2}$ 的预报进行了对比检验 [11]。李媛对银 川市空气污染指数开展检验分析, 得到了银川市API变化 特征, 并得出了空气污染指数预测模型[12]。宋丹等对比 检验了自建的空气质量指数预报模型和CUACE模式, 发 现多元线性逐步回归和BP神经网络方法对空气质量预报 具有较好的效果 $[13]$ 。

宁夏雨雪稀少、气候干燥、日照充足、风大沙多, 冬 季气候寒冷, 采暖期长, 主要燃料以煤和天然气为主。2004 年以来, 宁夏提出以天然气替代以煤为主的供热形式, 并
开展了试点工作, 但推进速度相对缓慢; 从2017年开始到 2018年, 宁夏根据“持续实施大气污染防治行动、打赢蓝 天保卫战”的工作方针, 以余热资源为主来调整供热用能 结构, 开始大规模采用天然气供热。同时, 宁夏处于黄土 高原西北部边缘地区, 西（西北）、北、东三面环沙, 西 侧的腾格里沙漠、巴丹吉林沙漠, 北侧的乌兰布统沙漠和 东侧的毛乌素沙地, 为输入型沙尘天气过程提供了充足的 沙源, 遭遇大风且低层大气层结不稳定时极易起沙形成沙 尘甚至沙尘暴天气，沙尘暴和二次扬尘及烟尘的排放导致 悬浮颗粒物污染严重[14-15]。本文通过开展空气质量预报 检验评估, 了解空气质量预报效果, 为进一步治理和控制 大气污染, 改进当前预报模式效果提供参考。

\section{2. 资料与方法}

\section{1. 观测点及资料介绍}

本文选取宁夏五市（银川、石嘴山、吴忠、中卫、固 原）2015年1月1日至2018年12月31日逐日空气质量实况监 测值和预报值开展检验评估。

其中空气质量实时监测数据来自环保部门公开数据, 要素包括逐日空气质量指数、等级、大气污染物 $\mathrm{PM}_{10}$ 、 $\mathrm{PM}_{2.5} 、 \mathrm{SO}_{2} 、 \mathrm{NO}_{2} 、 \mathrm{CO}$ 逐日浓度和 $\mathrm{O}_{3}$ 浓度八小时滑动平均 值、污染天气的首要污染物类型; 空气质量预报数据来源 于宁夏气象服务中心发布的 72 小时内逐 24 小时的空气质 量预报, 预报要素内容与实况相同。

\section{2. 检验指标和方法}

空气质量指数预报检验方法: 为了对研究时段五市空 气质量指数预报效果进行客观定量的对比分析, 本文采用 空气质量等级预报的 TS评分、漏报率PO、空报率 $\mathrm{NH}$ 、指 数预报的平均绝对误差MAE四种评价指标, 对预报效果进 行评价[16]。

污染物浓度预报效果检验: 由 $\mathrm{PM}_{10} 、 \mathrm{PM}_{2.5} 、 \mathrm{NO}_{2} 、 \mathrm{SO}_{2}$ 、 $\mathrm{CO}$ 逐日浓度及 $\mathrm{O}_{3}$ 浓度八小时滑动平均监测数据可知,宁夏 首要污染物主要包括 $\mathrm{PM}_{10} 、 \mathrm{PM}_{2.5} 、 \mathrm{O}_{3}$, 因此本文选择这 3 种污染物, 从归一化偏差MNE方面对污染物浓度预报效果 进行评估, 并利用TS评分、漏报率 $\mathrm{PO}$ 、空报率NH对首要 污染物类型预报进行检验。

(1)TS评分、漏报率PO、空报率 NH

$$
\begin{gathered}
\mathrm{TS}=\frac{\mathrm{NA}}{\mathrm{NA}+\mathrm{NB}+\mathrm{NC}} \times 100 \% \\
\mathrm{PO}=\frac{\mathrm{NB}}{\mathrm{NA}+\mathrm{NB}} \times 100 \%
\end{gathered}
$$




$$
\mathrm{NH}=\frac{\mathrm{NC}}{\mathrm{NA}+\mathrm{NC}} \times 100 \%
$$

计算公式如上。其中, NA为AQI等级或某首要污染物 预报正确次数; $\mathrm{NB}$ 为漏报次数, 即 $\mathrm{AQI}$ 等级预报不在某等 级内, 而实况出现在该等级的次数,或实况出现而预报未 出现某首要污染物的次数; $\mathrm{NC}$ 为空报次数, 即 $\mathrm{AQI}$ 等级预 报在某等级内而实况未出现在该等级的次数, 或预报出现 而实况未出现某首要污染物的次数。评估空气质量等级时, TS评分代表对各等级空气质量预报的准确程度; 评估首要 污染物时, TS评分反映了对各首要污染物有效预报的准确 性。漏报率和空报率分别反映对某首要污染物或某空气质 量等级的漏报次数和空报次数与实际出现次数的比值, 数 值越小代表预报效果越好。

(2) 平均绝对误差MAE

平均绝对误差MAE计算公式如下:

$$
\mathrm{MAE}=\frac{1}{\mathrm{n}} \sum_{i=1}^{n}\left|F_{i}-O_{i}\right|
$$

其中 $\mathrm{F}_{\mathrm{i}}$ 为第 $\mathrm{i}$ 天预报值, $O_{\mathrm{i}}$ 为第 $\mathrm{i}$ 天实况监测值, $\mathrm{n}$ 为样 本数。平均绝对误差反应某段时间内预报值和观测值偏差 的绝对值的平均值。

\section{(3) 归一化偏差MNE}

考虑各污染物浓度基数相差较大, 采用归一化偏差 MNE反应各污染物浓度实测值与预报值偏差的相对程度, 某污染物浓度预报归一化偏差MNE计算公式如下:

$$
\mathrm{MNE}=\frac{1}{\mathrm{n}} \sum_{\mathrm{i}=1}^{\mathrm{n}} \frac{\left|\mathrm{F}_{\mathrm{i}}-\mathrm{O}_{\mathrm{i}}\right|}{\mathrm{O}_{\mathrm{i}}}
$$

其中 $\mathrm{F}_{\mathrm{i}} 、 O_{\mathrm{i}} 、 \mathrm{n}$ 与(4)式意义同。

\section{3. 空气质量指数及首要污染物浓度分布特征}

\section{1. 空气质量指数 $A Q I$ 分布特征}

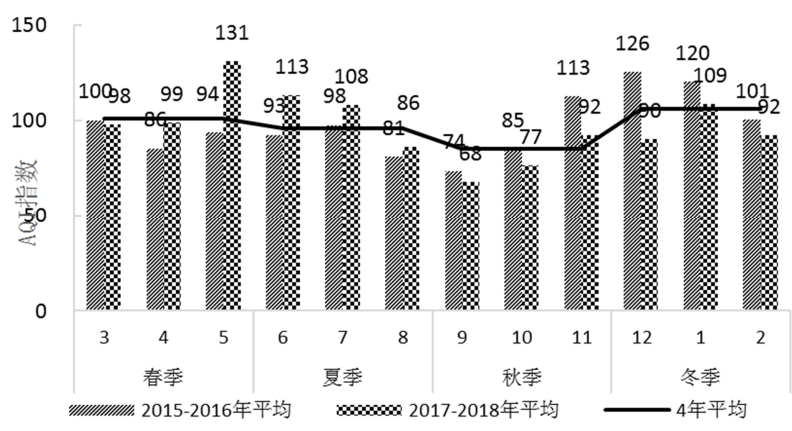

图1 2015-2016年和2017-2018年月、季平均全区平均AQI指数对比。

对比分析2015-2016年和2017-2018年的逐月平均AQI 指数（图1），可以看到，2017年前后AQI指数月分布特 征有了明显变化。2015-2016年11月到来年3月维持较高水 平, 普遍高于 100 , 其中 12 月 AQI值最大, 为 126 (轻度污 染），是空气质量最差的月份；而2017-2018年则是5月到 7 月以及 1 月较差, 其中 5 月空气质量最差, AQI指数达 131 (轻度污染)。从图中还可以看出, 两个统计时段中夏秋 两季空气质量均较好, 其中9月 AQI值最小, 分别为74 (良)、
68（良），是全年空气质量最好的月份。2015-2016年的 4-8月逐月平均AQI值均低于2017-2018年，而其余月份 2015-2016年高于2017-2018年，尤其是11月以后到来年3 月（也即每年供暖期），2017-2018年较2015-2016年的空 气质量指数低约 $17 \%$, 表明政府将供暖方式转换为天然气 这一举措对降低大气污染是十分有效地。

从季平均值来看 (图1曲线), 秋季空气质量最好, $\mathrm{AQI}$ 平均值为 85 ; 冬季空气质量最差, $\mathrm{AQI}$ 平均值为 106 ; 春夏两季空气质量指数季节平均值分别为 101 和 96 。

从AQI分级统计结果来看（图2a）, 发现全区空气质 量为良的天数占比最大, 为 $66.1 \%$; 其次为轻度污染, 占比 $25.7 \%$; 中度污染占比 $5.4 \%$; 优和重度污染所占比重小, 约为 $1.0 \%$; 严重污染等级所占比重不足 $0.5 \%$ 。从两个时段 对比来看（图2b），2017-2018年，优、良等级的比例较 2015-2016年分别增加 $1.5 \%$ 和 $0.4 \%$, 而污染等级则从轻度 到重度分别降低 $1.3 \% 、 0.8 \% 、 0.1 \%$, 这与五市供暖方式 的改进有关, 与前文的分析结果相一致。另外, 严重污染 的比例2017-2018年较2015-2016年高 $0.4 \%$, 这与 2018 年 1 月的连续7天的重污染天气有关, 与当年1月初静稳少风的 天气背景有关。

从不同季节各空气质量等级占比来看 (图2c), 各季 均以空气质量等级为良的天数占比最大, 轻度污染次之。 四季中以冬季空气质量在轻度污染及以上污染等级的天 数所占比重最大, 超过 $44 \%$; 秋季空气质量等级为良和优 的天数所占比重超过 $80 \%$, 是四季中污染天数占比最低的 季节。同时可以看出, 秋季空气质量未出现严重污染等级, 春季空气质量未出现优等级。
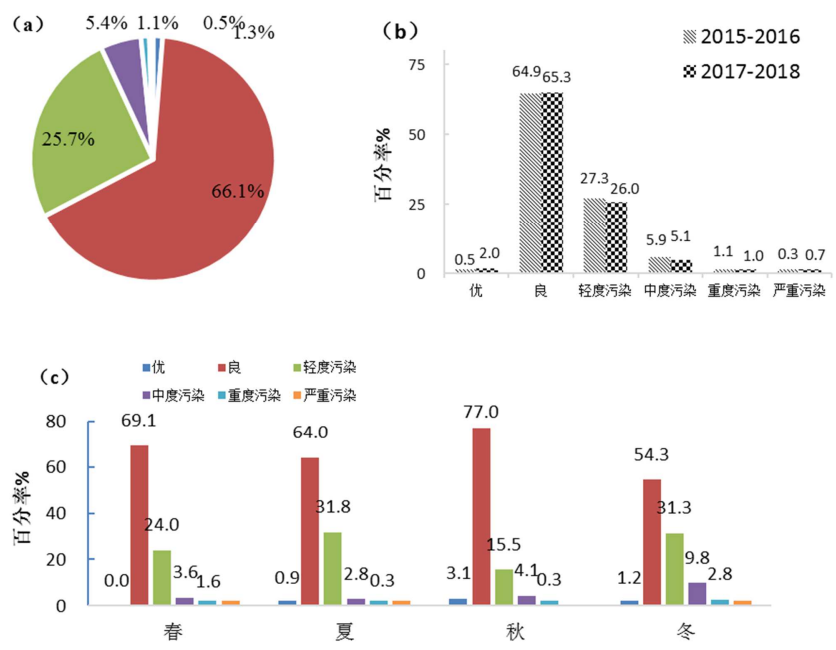

图2 全区平均AQI指数占比分析：（a）2015-2018年;（b）2015-2016 与2017-2018对比; (c) 季节分布。

\section{2. 首要污染物类型分布及浓度变化特征}

2015-2018年首要污染物类型包括 $\mathrm{PM}_{2.5} 、 \mathrm{O}_{3} 、 \mathrm{PM}_{10}$ 和 $\mathrm{SO}_{2}$, 四者占比依次下降（图3a）。其中 $\mathrm{PM}_{2.5}$ 出现概率最 大, 占比 $54.8 \% ; \mathrm{O}_{3} 、 \mathrm{PM}_{10}$ 次之, 分别占比 $24.3 \% 、 18.9 \%$; $\mathrm{SO}_{2}$ 出现概率最小, 仅为 $1.0 \%$, 因此本文重点分析前三种 首要污染物。 

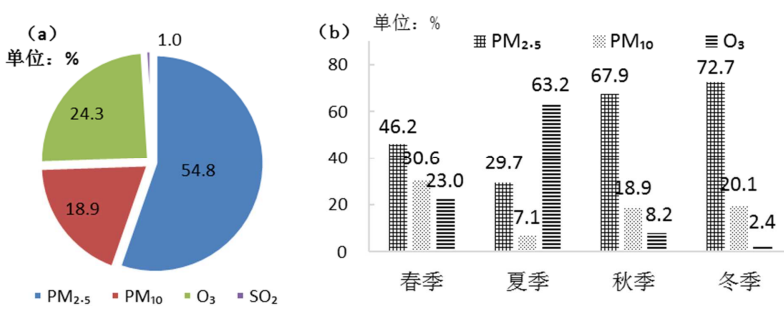

图3 2015-2018年首要污染物类型占比（a）及季节分布(b)。

各首要污染物出现概率均具备一定的季节分布特征 (图3b)。 $\mathrm{PM}_{2.5}$ 秋冬两季较高, 占比在 $70 \%$ 左右, 春季次 之 $(46.2 \%)$ ，夏季最低 $(29.7 \%) ; \mathrm{PM}_{10}$ 春季较高（占 比为 $30.6 \%)$, 秋冬季次之 (20\%左右), 夏季最低 $(7.1 \%)$; 而 $\mathrm{O}_{3}$ 则有明显不同特征, 夏季最高（占比 $63.2 \%$ ), 春季 次之 $(23 \%)$, 秋 $(8.2 \%)$ 冬 $(2.4 \%)$ 两季最低。另外, 图3b中还可分析得到各季节首要污染物出现概率变化特 征。其中春、秋、冬三个季节, 首要污染物类型分布规律 较为一致, 按首要污染物占比由大到小依次为 $\mathrm{PM}_{2.5} 、 \mathrm{PM}_{10}$ 、 $\mathrm{O}_{3}$; 而夏季依次为 $\mathrm{O}_{3} 、 \mathrm{PM}_{2.5} 、 \mathrm{PM}_{10}$ 。总体来说, 春季重 点关注的首要污染物为 $\mathrm{PM}_{10}$, 夏季重点关注 $\mathrm{O}_{3}$, 秋、冬季 重点关注 $\mathrm{PM}_{2.5}$ 。

\section{4. 预报检验结果}

\section{1. 空气质量等级预报检验}

通过检验可知（图略），现有预报模式对空气质量等 级预报效果不太理想, 在不区分空气质量等级的情况下来 看，整体预报的TS评分在 $20 \%-40 \%$ 之间，漏报率和空报率 较高, 在 $40 \%-70 \%$ 之间。从年际变化来看,全等级预报的 TS评分逐年递增, 2018年达到36\%, 表明订正能力在逐步 提高; 漏报率和空报率呈递减趋势, 由 2015 年 $60 \%$ 以上, 下降到2018年的 $40 \%$ 左右。从不同预报时次看, 各预报时 次的预报效果差异并不明显。

从不同等级预报效果来看, 除良等级的空气质量预报 相对较好以外, 其他等级空气质量预报的 TS评分均比较低 （低于 $20 \%$ ）。具体来看, 当空气质量等级为良时, 预报 的TS评分逐年递增且维持较高水平，其中 2018 年达到 $50 \%$ 以上; 当空气质量等级为轻度污染时, 各年际各时效的 TS 评分虽然水平不高 (10-20\%) 但相对稳定，2015年的72 小时预报最高; 当空气质量等级分别为优、中度污染、重 度污染及严重污染时, TS评分表现为波动性低值, 可以看 出, 针对上述四个等级的预报, 除个别年份个别时效预报 的TS评分相对高以外, 其余年份和时效的预报均几乎没有 参考价值。

除空气质量等级为良时, 漏报率呈逐年下降趋势外 （由2015年的60\%下降到2018的20\%左右）, 其余各等级 预报的漏报率总体上随年际变化增大, 表明该预报针对良 等级的空气质量预报相对具有比较好的参考意义。对于轻 度 (中度) 污染等级, 漏报率由 2015 年的 $60 \%(70 \%)$ 左 右增加到 2018 年的 $80 \%(90 \%)$ 以上。

空报率的评分结果相比漏报率则显示出较为稳定的 特征, 各等级预报的空报率均在一定的水平上波动。按优、
良、轻度污染、中度污染、重点污染、严重污染的顺序, 依次稳定在 $98 \% 、 30 \% 、 72 \% 、 90 \% 、 97 \% 、 99 \%$ 附近。

结合图2（a）可知, 研究时段内, 全区平均优、中度、 重度及严重污染等级天气所占比重小, 这可能是影响预报命 中率偏低, 漏报率和空报率较高的其中一个原因。以上分析 说明研究时段内, 虽然现有预报模式对空气质量等级预报的 整体预报效果有所提升, 但针对各不同等级空气质量的预报 效果并不都是提升的, 还需对预报方法进一步改进优化。

\section{2. 污染物浓度预报检验}

对污染物浓度预报进行检验（图4a-c）可知, $\mathrm{PM}_{2.5}$ 浓度预报的归一化偏差逐年减小, 其中秋冬季减小幅度最 为明显（图4a）。2015年各季差异最为明显, 冬季归一化 偏差达到 2.8；2016-2018年，归一化偏差多集中在0.5-1.0 之间，同时季节差异减小。可以看出，2018年各季的归一 化偏差相较2015年同期减少了 1/2-6/7, 说明研究时段内, $\mathrm{PM}_{2.5}$ 浓度预报水平逐年提高, 2018年预报效果明显优于 前三年。各年度归一化偏差均呈现冬高夏低的规律, 即夏 季预报效果最佳, 冬季预报效果最差, 现有预报模式对于 低浓度 $\mathrm{PM}_{2.5}$ 的预报能力优于对其高浓度时的预报。
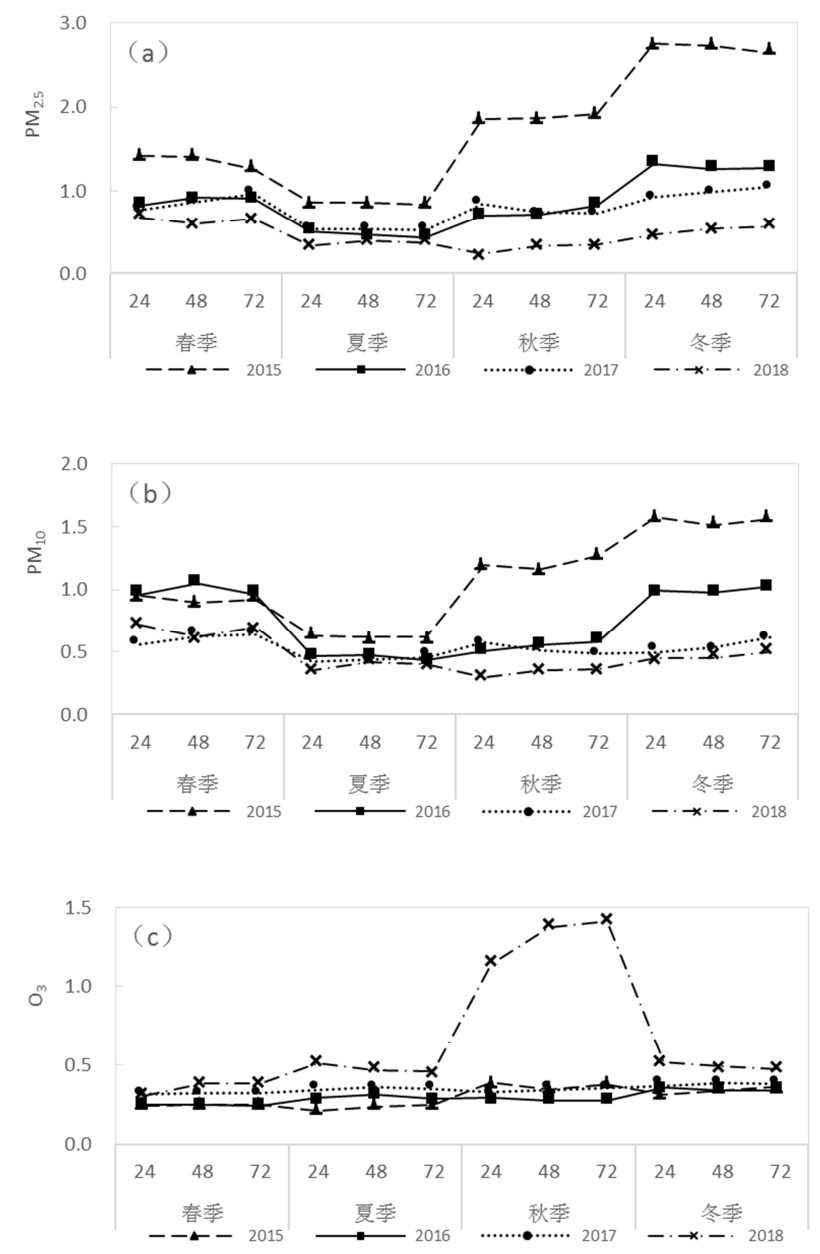

图4 2015-2018年 $\mathrm{PM}_{2.5}$ （a）、 $\mathrm{PM}_{10}$ （b）、 $\mathrm{O}_{3}$ （c）三种主要污染物浓度 预报归一化偏差。 
由图 $4 \mathrm{~b}$ 可知, 对于 $\mathrm{PM}_{10}$ 浓度预报, 从时间变化来看, 2018年归一化偏差整体上最小，各季归一化偏差集中在 0.3-0.7之间。2015年最大, 尤其冬季达到了 1.6。说明研究 时段内 $\mathrm{PM}_{10}$ 浓度预报效果随年际变化逐步改进, 整体上 2018年预报效果明显优于前三年, 尤其是秋冬季的归一化 偏差减少最为明显。从不同季节预报效果看, 各年度均以 夏季归一化偏差最小, 冬春两季最大, 且归一化偏差的季 节差异逐年减小。

由图 $4 \mathrm{c}$ 可知, 对于 $\mathrm{O}_{3}$ 浓度预报, 从不同年份来看, 2015-2017年各季归一化偏差集中在0.2-0.4, 年际差异较小, 且不同季节、不同预报时次归一化偏差的差异不明显。 2018年 $\mathrm{O}_{3}$ 浓度预报的归一化偏差高于其他年份, 尤其是秋 季的归一化偏差达到了 1.3 , 与前三年同期相比发生突变 猛增, 其他各季归一化偏差略高于前三年, 在0.3-0.6之间。 可以看出, 研究时段内对 $\mathrm{O}_{3}$ 浓度的预报效果未有所改进, 2018年预报效果差于前三年。

比较三种主要污染物浓度预报的归一化偏差, 结合污 染物浓度实测数据, 发现2015-2017年, 现有预报模式对 $\mathrm{O}_{3}$ 浓度预报的归一化偏差小于 $\mathrm{PM}_{2.5}$ 和 $\mathrm{PM}_{10}, 2018$ 年情况 相反, $\mathrm{O}_{3}$ 浓度预报的归一化偏差最大。综合以上分析, 研 究时段内, 现有预报模式针对 $\mathrm{PM}_{2.5} 、 \mathrm{PM}_{10}$ 浓度预报效果 在逐年改进，而针对 $\mathrm{O}_{3}$ 浓度预报的能力在降低; 2018年以 前针对 $\mathrm{O}_{3}$ 浓度的预报效果最优, 2018年针对 $\mathrm{PM}_{2.5} 、 \mathrm{PM}_{10}$ 浓度的预报能力已经超过了对于 $\mathrm{O}_{3}$ 浓度的预报能力; 不同 预报时次对于三种主要污染物浓度预报的归一化偏差无 明显差异，即不同预报时次的预报效果相当。

\section{3. 首要污染物类型预报检验}

从全区三种首要污染物类型预报评分结果来看 (图5), 2015-2017年, 针对首要污染物类型为 $\mathrm{PM}_{2.5}$ 的污染天气, $\mathrm{TS}$ 评分明显高于 $\mathrm{PM}_{10}$ 和 $\mathrm{O}_{3}$ （图5a）, 尤其2015年达到了 $60 \%$ 。同时漏报率（图5b) 与空报率（图 $5 \mathrm{c}$ ) 相较其他两 种污染物也较小。2018年情况相反, $\mathrm{PM}_{10}$ 和 $\mathrm{O}_{3}$ 的预报 TS 评分相当, 接近 $40 \%$, 明显高于 $\mathrm{PM}_{2.5}$ 的预报, 而漏报率和 空报率也明显低于 $\mathrm{PM}_{2.5}$ 。从年际变化来看, 2018年以前, $\mathrm{PM}_{10}$ 和 $\mathrm{O}_{3}$ 的预报 TS评分随年际变化保持相对平稳或小幅 度上升, 2018年TS评分明显增大, 同时漏报率和空报率随 年际变化总体呈下降趋势; $\mathrm{PM}_{2.5}$ 的预报结果则呈现与此 相反的变化趋势, TS评分随年际变化减小, 漏报率随年际 变化增大, 空报率在2018年以前保持平稳, 2018年明显增 大。以上分析可以得出, 2018年以前, 该预报对于首要污 染物类型为 $\mathrm{PM}_{2.5}$ 的预报效果明显优于其他两种污染物; 2018 年对于首要污染物类型为 $\mathrm{PM}_{10}$ 和 $\mathrm{O}_{3}$ 的预报效果优于 $\mathrm{PM}_{2.5}$ 。值得注意的是, 首要污染物类型的预报效果随着 预报时次变化并未出现明显差异, 即不同时次预报对首要 污染物类型的预报效果基本一致。

由实况监测数据可知, 2015-2017年, 全区污染天气 中 $58 \%-83 \%$ 首要污染物均为 $\mathrm{PM}_{2.5}$ (图略)，2018年首要 污染物主要为 $\mathrm{PM}_{10}$ 和 $\mathrm{O}_{3}$ 。受大规模地改用天然气供暖的影 响, 2018年首要污染物为 $\mathrm{PM}_{2.5}$ 的天数占比仅 $9 \%$; 这可能 是导致2018年对于首要污染物为 $\mathrm{PM}_{2.5}$ 的污染天气预报命 中率偏低的原因之一。
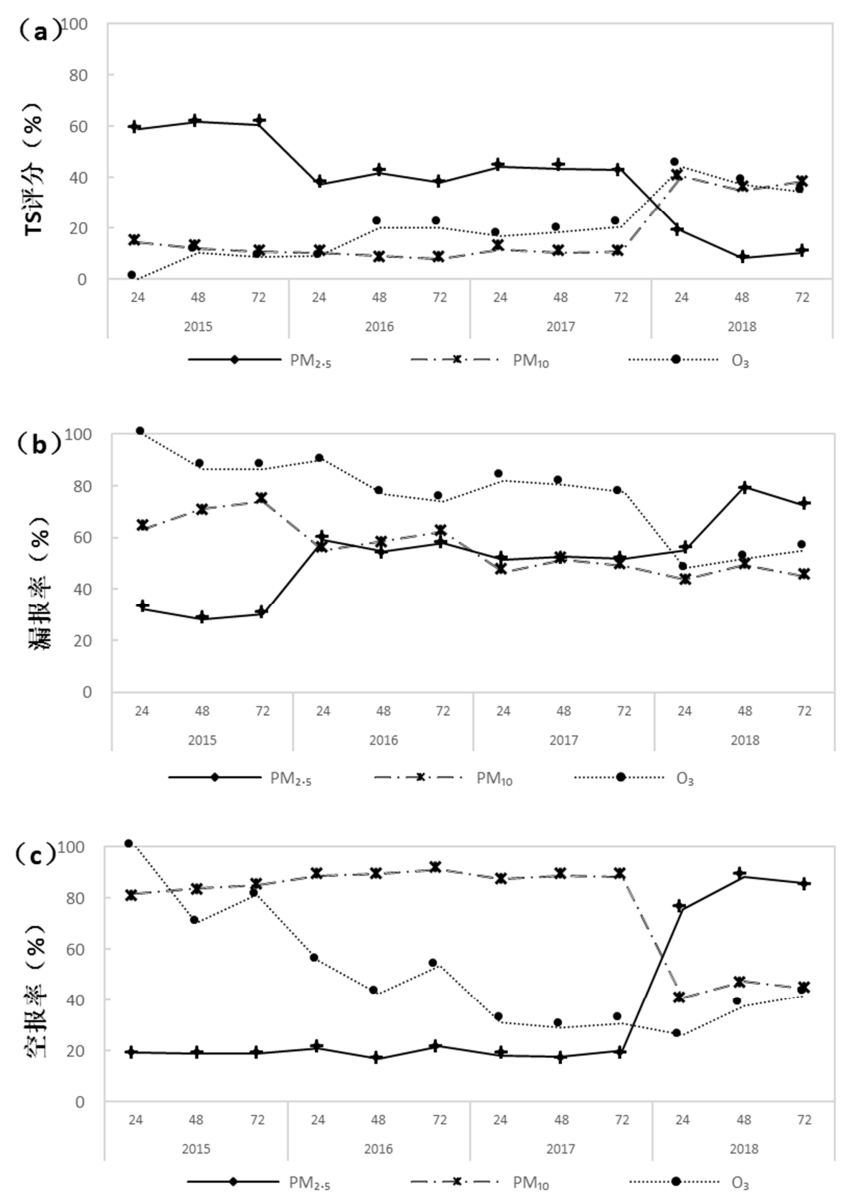

图5 2015-2018年三种首要污染物类型预报的TS评分(a)、漏报率（b）、 空报率（c）。

\section{5. 结论}

(1) 该预报对空气质量等级的预报效果不太理想, 具有较大订正空间。空气质量等级预报平均 TS 评分在 20\%-40\%之间, 漏报率和空报率较高。随年际变化, TS 评分呈递增趋势, 漏报率和空报率呈递减趋势。

(2) $\mathrm{AQI}$ 指数预报的平均绝对误差随污染等级增加 总体上呈递增趋势。2015-2016年, 各季节AQI指数预报 的平均绝对误差变化呈现夏低冬高的规律。而2017-2018 年, 季节变化呈现秋低春高的规律。AQI指数预报的平 均绝对误差随年际变化减小, 2018 年对 AQI指数的预报 效果最佳。

（3）该预报针对 $\mathrm{PM}_{2.5} 、 \mathrm{PM}_{10}$ 浓度预报效果在逐年 改进, 而针对 $\mathrm{O}_{3}$ 浓度预报的能力在降低, 2018年以前对 于 $\mathrm{O}_{3}$ 浓度的预报效果最优, 2018 年对 $\mathrm{PM}_{2.5} 、 \mathrm{PM}_{10}$ 浓度的 预报能力已经超过了 $\mathrm{O}_{3}$ 。 $\mathrm{O}_{3}$ 的生成主要受前体物和大气 化学过程控制, 但气象条件直接影响臭氧的光化学反应 和扩散传输, 是局地发生臭氧污染过程的重要因素, 因 此如何综合考虑这些因素的影响, 对提高 $\mathrm{O}_{3}$ 的预报能力 尤为重要。

（4）2018年以前, 对于首要污染物类型为 $\mathrm{PM}_{2.5}$ 的预 报效果明显优于其他污染物, 2018年对于首要污染物类型 为 $\mathrm{PM}_{10}$ 和 $\mathrm{O}_{3}$ 的预报效果优于 $\mathrm{PM}_{2.5}$ 。 


\section{6. 讨论}

从分析结果来看，无论是对于空气质量等级预报、 $\mathrm{AQI}$ 指数预报、污染物浓度预报还是首要污染物类型预报, 该模式对 $24 \mathrm{~h} 、 48 \mathrm{~h} 、 72 \mathrm{~h}$ 预报时次的预报效果差异并不明 显, 即该预报对于以上要素的预报能力并未随预报时效缩 短而出现较为明显的提升。

\section{参考文献}

[1] 周丽,徐祥德, 丁国安,等.北京地区气溶胶 $\mathrm{PM}_{2.5}$ 粒子浓度的 相关因子及其估算模型 [J].气象学报,2003,61(6):761-768.

[2] 魏玉香,童尧青,银燕,等.南京 $\mathrm{SO}_{2} 、 \mathrm{NO}_{2}$ 和 $\mathrm{PM}_{10}$ 变化特征及其 与气象条件的关系 [J]. 大气科学学报,2009,32(3):451-457.

[3] 李晓岗,马雁军,王扬锋,等.基于CUACE系统沈阳地区春季 空气质量预报的检验及修正 $[\mathrm{J}]$. 气象与环境学 报,2016,32(6):10-18.

[4] 麦健华,于玲玲,邓涛.等.基于GRAPES-CMAQ的中山市空 气质量预报系统预报效果评估 [J]. 热带气象学 报,2018,34(1):78-86.

[5] 冯震,谷新波.呼和浩特市2015年冬季空气质量指导预报检 验分析[J].内蒙古气象,2018,(2):17-29.
[6] 刘慧,饶晓琴,张恒德, 等.环境气象业务数值模式预报效果对 比检验[J].气象与环境学报,2017,33(5):17-24.

[7] 张珺,王式功,杜亮亮, 等. 基于 $\mathrm{BP}$ 神经网络的河北中南部空 气质量预报研究[J].江西农业学报,2019,31(5):96-102.

[8] 杨关盈,邓学良,吴必文,等.基于CUACE模式的合肥地区空 气质量预报效果检验[J].气象与环境学报,2017,33(1):51-57.

[9] 张璘, 张祥志,茅晶晶, 等. 江苏省空气质量预报准确度及改进 方法分析[J].中国环境监测,2017,33(6):17-24.

[10] 岳旭, 蒋璐君, 吴琼.2018. 南昌市空气质量预报产品检验分析 及统计订正试验 $[\mathrm{J}]$.气象与减灾研究,41(3):212-218。

[11] 王晓敏,陈静,钤伟妙,等.新标准下空气质量预报指导产品对 比检验 $[J]$.气象与环境科学,2016,39(3):97-103.

[12] 李媛. 银川市空气污染指数的分析与预测 [J]. 宁夏大学学报 (自然版),2012,33(4):416-419.

[13] 宋丹,夏晓玲,何玉龙,等.贵阳市空气质量预报方法与效果检 验 $[\mathrm{J}]$.气象与环境科学,2019,42(1):93-100.

[14] 米文宝,柇新刚. 宁夏城市污染的现状、趋势及对策[J].中国 地质大学学报,2007,7(3):23-26.

[15] 姜玲. 银川市城市环境质量状况及污染防治[J]. 宁夏工程技 术,2003,2(1):16-18.

[16] 中国环境科学研究院, 中国环境监测总站.CB3095 -2012, 环 境空气质量标准[S].北京:中国环境科学出版社,2016. 